\title{
Not a One-track
}

Approach

\section{Dear Reader,}

In the discussions about synthetic fuels that I take part in on a regular basis, someone almost always brings up the argument that because of the huge amounts of fuel required and because of the lack of an alternative to the combustion engine in aviation and shipping, it is in these industries that e-fuels should primarily be used. The speaker then claims that there would be none left over for road vehicles. Processes like carbon capture, electrolysis and FischerTropsch are frequently mentioned and at some point it almost always emerges that a large number of things are being lumped together which do not necessarily belong in the same context.

That is precisely what is happening with the Fischer-Tropsch process. It does not produce a finished synthetic fuel with all the properties that the chemists want. The application of heat and pressure to a synthesis of hydrogen and $\mathrm{CO}_{2}$ (actually carbon monoxide) results in a varied mix of hydrocarbon chains of different lengths, in other words, a synthetic form of crude oil. This mixture has an energy content that is far higher than that of gasoline or diesel and so the crude oil is ideal as a storage form for energy and as a means of transporting it to the refinery where conventional processes can be used to produce several different types of fuel. It is a mistake to think that only one kind of fuel, such as kerosene, can be manufactured from it.
When fossil crude oil is processed in a refinery, around $4 \%$ of the total mass is kerosene, $24 \%$ gasoline and $21 \%$ diesel and light heating oil. Another $14 \%$ consists of heavy oil plus various lubricants, naphtha and gases. It is true that these proportions can be adjusted in favor of certain products, but this always involves extra work and ultimately results in a product that is not cost-effective.

Therefore, if you need large quantities of synthetic kerosene for aircraft and heavy oil for shipping, the proportion of the other defossilized fuels produced will definitely be enough for road vehicles. A multi-track approach makes the most economic sense.

I hope you enjoy this issue of MTZ.

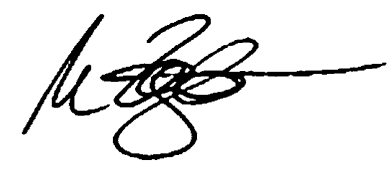

Marc Ziegler

Deputy Editor in Chief

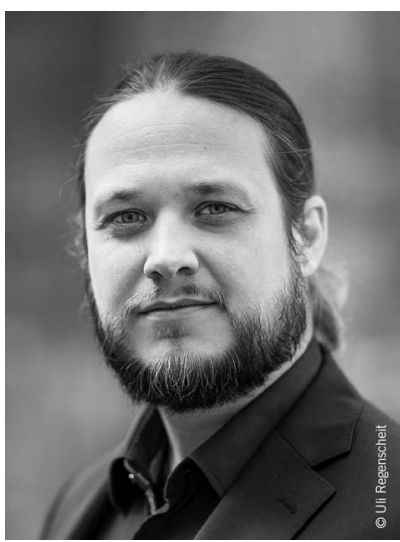

